\title{
Effects of a structured combined exercise intervention program on old participants mental health and well-being
}

\begin{abstract}
An intervention study was conducted to examine the changes in physical self-perceptions and self-esteem, as predictors of mental health and well-being, over the course of a 14 weeks combined exercise program in old people. Forty old participants were grouped into either an experimental group (EG; $M=69.70 ; S D=3.29)$ or a control group ( $C G ; M=71.10$; $\mathrm{SD}=3.42$ ). To assess changes in individual feelings about the physical self and global selfesteem participants filled the Physical Self-Perception Profile - clinical version (CPSPP) and the Rosenberg Self-esteem Scale (RSES) pre- and post-intervention. Present results evidence the potential impact of exercise participation on the development of positive selfconcept feelings in the physical domain over time. Results highlights a strong tendency for those who get involved in exercise programs to increase their levels of physical self when compared with those who do not participate. Self-esteem was confirmed to be a more stable psychological construct, less sensitive to the immediate effects of exercise participation.
\end{abstract}

Keywords: combined training, physical self-perceptions, CPSPP, old people
Volume 2 Issue 6 - 2018

\author{
José P Ferreira,' Joana R Leite,' Alain G \\ Massart,' Maria J Campos,' Guilherme \\ E Furtado,' Elsa R Silva,' Humberto M \\ Carvalho, ${ }^{2}$ Edith Filaire ${ }^{3}$ \\ 'Faculdade de Ciências do Desporto e Educação Física, \\ University of Coimbra, Portugal \\ ${ }^{2}$ Faculty of Physical Education, Federal University of Santa \\ Catarina, Brazil \\ ${ }^{3}$ Laboratoire CIAMS, EA4532, University of Orleans, France
}

Correspondence: José P Ferreira, Centro de Investigação do Desporto e da Atividade Física (UID/PTD/04/3/2016), Faculdade de Ciências do Desporto e Educação Física, Universidade de Coimbra, Estádio Universitário - Pavilhão III, Santa Clara, 3040-156 Coimbra, Portugal, Tel (+35I) 239802770, Fax (++35I) 239802779, Email jpferraira@fcdef.uc.pt

Received: November 21, 2017 | Published: December II, 2018

\section{Introduction}

Health organizations emphasize self-esteem as a central component of mental health and one of the strongest predictors of mental health and subjective well-being. ${ }^{1,2}$ It is often regarded as the single most important contribution to psychological well-being and an important aspect of quality of life, considered as a possible target for public health campaigns. ${ }^{3}$

Self-esteem is the evaluation that each individual usually maintains regarding himself, the way he expresses approval or disapproval attitudes towards himself as well as the extension individual beliefs about his own competence, significance and respectability. ${ }^{4}$ In other words, self-esteem is understood as the evaluative component of the self, it is the degree that the individual has of favorable perception of his own self. ${ }^{5}$ Positive self-esteem is seen as a basic feature of mental health, but also as a protective factor that contributes to better health and positive social behavior through its role as a buffer against the impact of negative influences. ${ }^{6}$ Low self-esteem is often associated with poor health behaviors and mental disorders ${ }^{6,7}$ such as depression, anxiety, ${ }^{9}$ substance abuse ${ }^{10,11}$ and violence and high-risk behaviors. ${ }^{12}$

Moreover, the physical self has emerged as a key component of identity and self-esteem occupying a unique position in the self-system. The body through its appearance, attitudes and abilities provides the substantive interface between the individual and the world, providing a key understanding to the construction of our identities, the basis of our self-esteem, and many of our behavior patterns. ${ }^{13}$
Additionally, in the last decade health professionals have been increasingly interested in the potential of exercise to prevent and treat mental health disorders and to improve the levels of psychological well-being of the general population. ${ }^{14}$ Regular exercise increases the social contact, improves the physical and mental health, and plays the important role to diminish chronic disease risk factors and to maintain body functions for older people. ${ }^{15}$

Cross-sectional studies have well established that regular exercise and physical activity is negatively associated with symptoms of anxiety and depression. ${ }^{16} \mathrm{~A}$ recent meta-analysis provided indication that exercise can improve the mental well-being of frail elders and that mental well-being in later life is modifiable through exercise and physical activity. ${ }^{17}$ Positive effects of exercise participation have been reported suggesting increases on older adults' self-efficacy that might improve more positive perceptions of well-being and effectively enhance quality of life. ${ }^{18-21}$ Other studies revealed that physical activity has an effective contribution for improving mood states, ${ }^{22}$ Self-esteem ${ }^{23,24}$ and life satisfaction ${ }^{19,25,26}$ in older adults, all important indicators of mental health and well-being.

Further evidence for these positive effects of exercise on mental health and well-being in old people have recently been provided as a guideline for physical activity and health policies in the United States, ${ }^{27}$ offering strong evidence base for both preventive and therapeutic benefits of physical activity and exercise for improving mental health and well-being of adults and old population. 
In spite of the important contribution of self-esteem and the physical self as mental health indicators and as predictors of positive emotional adjustments, not many studies used the Physical Self Model proposed by Fox \& Corbin $^{28}$ to describe how middle age adults and older adults evaluate their personal feelings in the physical domain and its relationship with global self-esteem. ${ }^{23,29-33}$

The purpose of the present study is to evaluate the effects of a 14-weeks structured combined exercise intervention program on old participants' physical self-perceptions and global self-esteem as predictors of mental health and well-being in comparison with an assessment-only control group. It is hypothesized that old people after participating in an combined exercise program would report more positive feelings about their physical self and global self-esteem, that is, more positive perceptions about their mental health and well-being than those not involved in any combined exercise program.

\section{Method}

\section{Participants}

Forty old participants aged from 65 to 81 years $(\mathrm{M}=70.40$; $\mathrm{SD}=3.36)$ were randomly selected from a bigger groups $(\mathrm{N}=251$; $\mathrm{M}=74.27$ and $\mathrm{SD}=7.32), 170$ females $(\mathrm{M}=73.84 ; \mathrm{SD}=7.39)$ and 81 males $(\mathrm{M}=75.17 ; \mathrm{SD}=7.14)$ participating in a regional community recreational program promoted by the City of Santa Maria da Feira, Portugal. An effort was made to recruit participants from different backgrounds and lived experiences. All participants obtained medical permission from their GP to participate in the exercise program. They were cognitively able to express themselves in an autonomous way as no Alzheimer, dementia or other cognitive limitative conditions were diagnosed.

\section{Instrumentation}

Some studies used the Physical Self-Perception Profile-PSPP ${ }^{28}$ with adults and older populations, ${ }^{23,29,30}$ however questions have been raised about its adequacy. ${ }^{29,33}$ The recently validated 18 -item clinical version of the Physical Self-Perception Profile - CPSPP ${ }^{31,34}$ was used to assess old peoples` self-perceptions in the physical domain. This instrument is a six subscale instrument (physical function, physical health, sport competence, body attractiveness, physical strength and physical self-worth) with three items per factor in a possible range from 3 to 12 points. The CPSPP version was developed by Fox et al. ${ }^{31}$ based on a pioneering work of Chase ${ }^{35}$ Its psychometric properties and internal consistency and reliability were assessed by Ferreira et al. ${ }^{34}$ using confirmatory factor analysis with a sample of 1002 old Portuguese participants and obtained adequate cutoff indexes values $(\mathrm{NFI}=0.89, \mathrm{CFI}=0.90, \mathrm{IFI}=0.90$ and $\mathrm{RMSEA} \leq 0.08)$.

Global Self-esteem (GSE) was assessed using the Rosenberg Selfesteem Scale-RSES. ${ }^{36}$ It is a ten item unidimensional scale that uses a 4-point Likert response format that varies from strongly agree to strongly disagree. Self-esteem is represented by the sum of all item scores providing a possible range of 10 to 40 with higher scores indicating higher self-esteem. Previous studies using RSES ${ }^{37}$ reported a reliability coefficient of $r=.75$. For the present study the test-retest reliability coefficient was $\mathrm{r}=.73$.

\section{Procedures}

For experimental design purposes two groups were defined: an experimental group (EG) of $n=20$ individuals aged from 66 to 77 years
$(\mathrm{M}=69.70, \mathrm{SD}=3.29)$ and a control group $(\mathrm{CG})$ of $\mathrm{n}=20$ individuals aged from 68 to 81 years $(\mathrm{M}=71.10, \mathrm{SD}=3.42)$. Experimental and control group participants were randomly selected among two hundred and fifty one elderly individuals attending a weekly sociocultural community program in the City of Santa Maria da Feira, Portugal. Permission was requested for participants' recruitment and staff cooperation. All participants expressed their written consent to participate in the study and no incentives were provided to them.

The purpose of the study was explained to all participants. They were tested individually due to the complexity of the questionnaires and age implications. Instruments were administrated using standardized instructions by the same research assistant. Interviewing techniques were used due to the low academic level of the participants and additional difficulties to understand some of the items from the CPSPP. One-to-one assistance was available at any time. Participants were assessed in two time moments, at time 0 (T0), i.e., at the beginning of the study and at time 1 (T1), 14 weeks later after intervention. During this 14 weeks period both the EG and CG maintained their regular weekly sociocultural community activities. The study was approved by the Ethics Committee of the Sport Sciences and Physical Education Faculty-University of Coimbra, Portugal and performed in accordance with the Declaration of Helsinki.

\section{Exercise intervention}

The intervention consisted of two combined exercise sessions per week for 14 weeks. Each session lasted for 55 minutes including warm-up, main session and cool-down. The main session comprised exercises to improve aerobic capacity, endurance strength and flexibility. Global aerobic work intensity varied during training sessions from $55 \%$ to $75 \%$ of participant's maximal heart rate (max HR). Exercise intensity was indirectly predicted using the Karvonen's formula to predict target heart rate but with maximal heart rate being calculated using a specific formula ${ }^{38}$ for elderly people ( $\max \mathrm{HR}=207$ bpm- $0.7 \mathrm{x}$ age) for safety reasons.

\section{Statistical analysis}

All variables were checked for normality. Descriptive statistics for all CPSPP sub-domains and for global self-esteem (GSE) were computed for the total sample. The assumption of normality was checked by the Kolmogorov-Smirnov test with Lilliefors' significance correction, and by visual inspection of normality plots. Test-retest reliability for CPSPP and for RSES was assessed based on replicate tests of the instruments to a sub-sample $(\mathrm{n}=10)$ of elderly individuals after a 16 days period. Within-subject modelling, based on unpaired t-test, was performed to compare groups at baseline (pre-intervention) and to investigate the differences in the changes with exposure to exercise intervention. Inferences about the true (population) values of the effect of the exercise intervention on participants' physical selfperceptions and self-esteem were based on the calculation of the $95 \%$ confidence limit for each effect was also calculated. ${ }^{39}$ The betweensubject standard deviation for each dependent variable was used to convert the changes in psychological profile into standardized [Cohen effect size (ES)] changes in the mean. Using Hopkins ${ }^{40}$ as a guide, effect sizes were considered as trivial $(\mathrm{d} \leq 0.2)$, small $(0.2<\mathrm{d}<0.6)$, moderate $(0.6<\mathrm{d}<1.2)$, large $(1.2<\mathrm{d}<2.0)$, very large $(2.0<\mathrm{d}<4.0)$ and nearly perfect $(\mathrm{d}>4.0)$. Statistical significance was set at $\mathrm{p} \leq 0.05$. All analyses were conducted with the statistics software IBM SPSS Statistics for Windows version 20.0 and the R statistical language package (http://cran.r-project.org). 


\section{Results}

Descriptive statistics for the CPSPP subscales and for GSE in EG and CG at baseline are summarized in Table 1. At baseline there were no significant differences between participants in groups EG and CG in both CPSPP subscales and GSE ( $p>0.05)$. Moreover, the effect sizes were minor at best in all variables, with the exception of body attractiveness where the differences between groups had moderate effect size. Thus, the old participants' in our study $(\mathrm{n}=40)$ revealed a similar psychological profile pre-intervention, indicating that homogeneity between the two groups pre-intervention was established.

Table 2 shows the effects of the exercise intervention in the experimental group, there were no differences in physical health, physical self-worth and global self-esteem during the 14-week exercise intervention. Noteworthy, the trend of changes for physical health and global self-esteem as consequence of the exercise intervention seems to be possibly, reflected by the small overlap of the $95 \%$ confidence limits. Potentially beneficial changes within the experimental group as consequence of the exercise intervention, were apparent in physical function (11.4\%, $<<0.05$, possibly beneficial), physical strength $(25.9 \%, p<0.01$, possibly beneficial) and sport competence $(28.1 \%$, $\mathrm{p}<0.01$, likely beneficial). Significant changes were apparent for body attractiveness, but the small magnitude of the effect size indicates that differences within the experimental group pre-and post-intervention were possibly trivial. The potentially beneficial trends observed within the experimental group seem to be confirmed when individual responses were compared with the control group (Figure 1). Figure 1 summarized the comparison between experimental and control group at pre-intervention, as well as the comparison of pre- and postintervention changes between groups.

Table I Characteristics of experimental and control groups at baseline

\begin{tabular}{lllll}
\hline & Experimental group $(\mathbf{n}=\mathbf{2 0})$ & Control group $(\mathbf{n}=\mathbf{2 0})$ & $\mathbf{P}$ & Practical inference \\
\hline Physical function & $7.90(2.19)$ & $6.95(1.64)$ & 0.13 & Possibly trivial \\
Physical health & $7.10(2.07)$ & $7.30(1.34)$ & 0.71 & Possibly trivial \\
Sport competence & $6.65(1.79)$ & $7.10(1.83)$ & 0.44 & Possibly trivial \\
Body attractiveness & $7.25(1.71)$ & $6.40(1.05)$ & 0.07 & Possibly trivial \\
Physical strength & $6.35(1.87)$ & $6.90(1.52)$ & 0.31 & Possibly trivial \\
Physical self-Worth & $7.60(0.99)$ & $6.95(1.43)$ & 0.10 & Possibly trivial \\
Global self-esteem & $22.70(2.11)$ & $23.65(1.90)$ & 0.14 & Possibly trivial
\end{tabular}

Table 2 Mean changes in psychological indicators pre- and post-intervention in the experimental group and chances that the true difference in the changes is substantial

\begin{tabular}{|c|c|c|c|c|c|}
\hline & Pre-intervention & Post-intervention & $\begin{array}{l}\text { Changes in mean, } \\
95 \% \mathrm{CL}(\%)\end{array}$ & $\begin{array}{l}\text { Coefficient of variation, } \\
95 \% \text { CL (\%) }\end{array}$ & $\begin{array}{l}\text { Effect size } \\
\text { (Practical inference) }\end{array}$ \\
\hline Physical function & $7.90(2.19)$ & $8.85(2.4 I)$ & I I. 4 (-2.6 to 26.5$)^{*}$ & $21.8(16.2$ to 33.4$)$ & $0.4 \mathrm{I}$ (Benefit possible) \\
\hline Physical health & $7.10(2.07)$ & $7.95(2.06)$ & I2.6 (-7.I to 36.4$)$ & 33.7 (24.7 to 52.8$)$ & $0.4 \mathrm{I}$ (Benefit possible) \\
\hline Sport competence & $6.65(1.79)$ & $8.50(2.12)$ & 28.1 (I I. 0 to 47.9$)^{* * *}$ & 24.2 (17.9 to 37.3$)$ & 0.95 (Benefit likely) \\
\hline Body attractiveness & $7.25(I .7 I)$ & $6.85(1.95)$ & $-6.8(-17.5 \text { to } 5.4)^{*}$ & 20.4 (I5.I to $31 . I)$ & 0.22 (Possibly trivial) \\
\hline Physical strength & $6.35(1.87)$ & $8.00(2.29)$ & $25.9(5.6 \text { to } 50.1)^{* *}$ & 30.4 (22.4 to 47.4$)$ & 0.79 (Benefit possible) \\
\hline Physical self-worth & $7.60(0.99)$ & $7.90(2.22)$ & $0.2(-12.7$ to 14.9$)$ & $23.0(17.1$ to 35.4$)$ & 0.19 (Possibly trivial) \\
\hline Global self-esteem & $22.70(2.11)$ & $23.75(2.40)$ & $4.5(-0.8$ to 10.2$)$ & $8.3(6.2$ to 12.3$)$ & 0.47 (Benefit possible) \\
\hline
\end{tabular}

$*_{p}<0.01 ; *^{*}<0.05$, comparisons between pre- and post-training based on paired-t statistic 

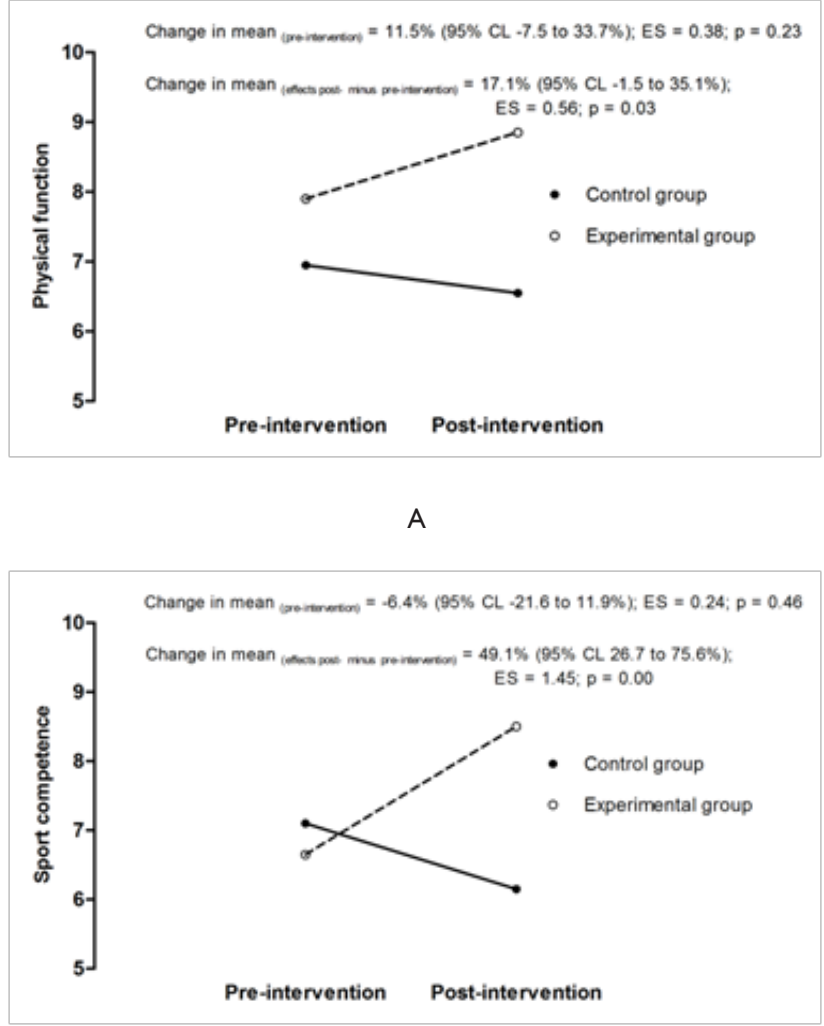

C

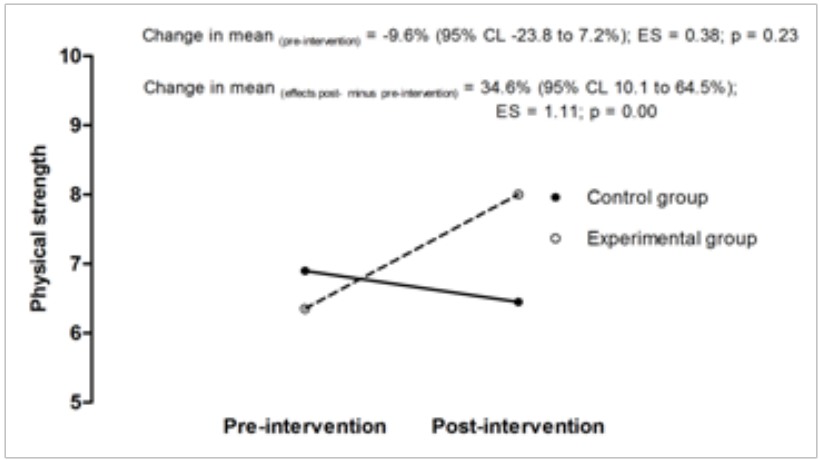

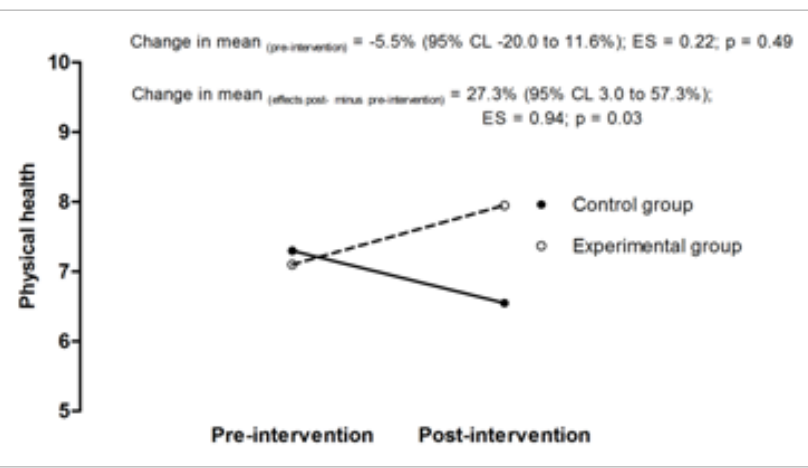

B

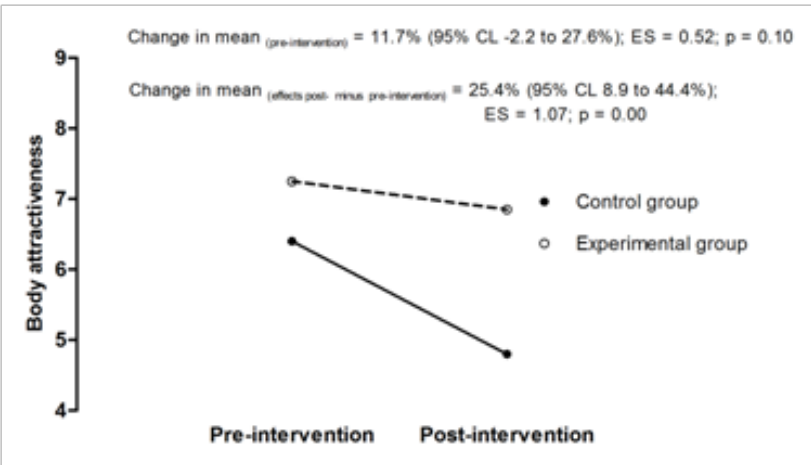

D

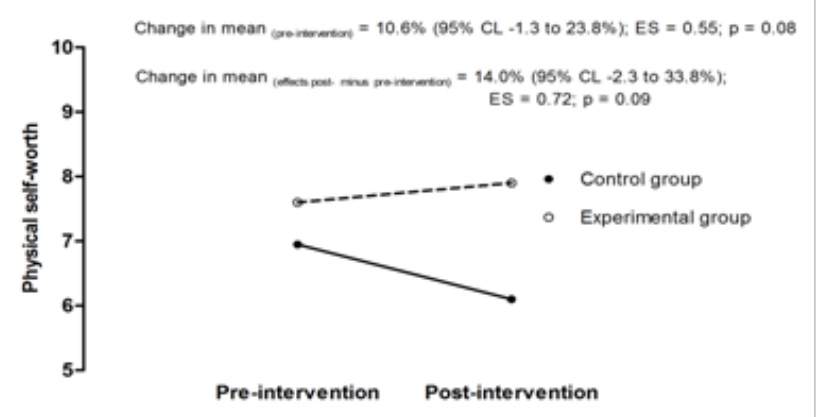

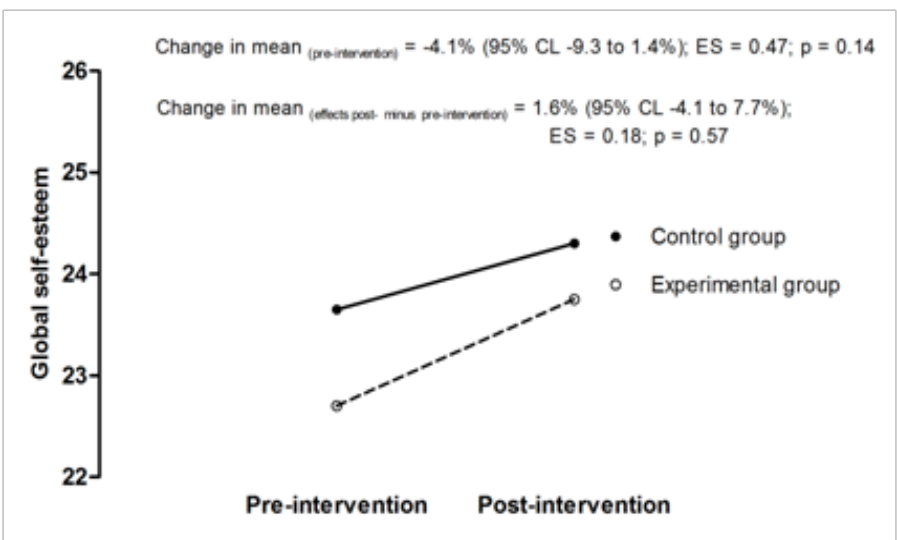

Figure I Comparison between experimental and control group at pre-intervention and comparison of pre- and post-intervention changes between groups.

Citation: Ferreira JP, Leite JR, Massart AG, et al. Effects of a structured combined exercise intervention program on old participants mental health and wellbeing. Hos Pal Med Int Jnl. 20I8;2(6):370-376. DOI: 10.15406/hpmii.2018.02.00I28 


\section{Discussion}

The aim of the study was to find evidence for the effects of a regular exercise program on elderly participant's physical self-perceptions and global self-esteem.

Results revealed that both EC and CG participants had similar values for self-esteem and perceived physical self before intervention (T0). Thus, the overall positive effects of exercise intervention on self-esteem and perceived physical self-scales in comparison to control group support potential beneficial effects of exercise to older populations.

Old participants in the EG increased their mean score values for all CPSPP subscales and for GSE, between the beginning and the end of the exercise intervention program, except for the body subdomain. This increment was significant for physical function, sport competence and physical strength.

Old participants exposed to exercise showed increasing levels of confidence about their athletic ability, about attending sport environments and about their level of strength and confidence in situations requiring strength from $\mathrm{T} 0$ to $\mathrm{T} 1$. On the other hand, results showed a significant decrease on old peoples' feelings about the body and the perceived ability to keep it attractive. Old participants from the EG decreased their feelings about their body attractiveness as a result of exercise, however that reduction was even greater in the CG from T0 to T1 (Figure 1D).

There is a large body of evidence indicating the positive impact of exercise on individual well-being, one particular facet of which is focused on the individual feelings toward the body. ${ }^{41}$ Several studies investigated the effects of exercise programs on older adults and found improvements for both older men and women on perceived physical appearance, ${ }^{42}$ body self-concep ${ }^{43}$ and social physique anxiety. ${ }^{44}$

Present results may be related to participants' high age average (70.40 years) and express the impact of the aging process. Moreover, the increased dissatisfaction with the body in the EG may also be due to an increasing of self-awareness about the body, figure or physique, as a result of exercise participation. Many of the participants took part in an exercise program for the first time in their lives and regular contact with exercise may expose more their inabilities to maintain the body attractive and in good shape, slightly increasing dissatisfaction and criticism about it.

Nevertheless, elderly participants not exposed to exercise (CG) decreased their mean score values for all CPSPP subdomains between $\mathrm{T} 0$ and $\mathrm{T} 1$. This decrease was statistically significant in sport competence and body attractiveness domains.

Overall, the comparison between old people exposed to exercise intervention with control peers reveals a progressive gap increment between participants' physical self-perceptions as result of the intervention program (Figure 1). It was evident for the perceived physical self that the 14 weeks exercise program exposure had a positive and potential beneficial effect while the participants not exposed to exercise presented a negative trend of decrements on their self-perception values in all CPSPP subdomains.

Finally, variation of self-esteem values pre- and post-intervention was significant in neither groups. Although some changes in selfesteem have been reported across life span, the results from the present study are consistent with the idea that self-esteem is a relatively stable construct over time ${ }^{45}$ and that exercise participation is often associated with small changes in GSE. ${ }^{46}$ Further evidence for this limited variation in elderly was recently suggested by Gothe et al..$^{23}$ when reporting a relatively flat self-esteem trajectory variation across a 12 months exercise program participation. From an intervention perspective, lower sub domain levels of esteem are clearly easier to target and modify than the individual's overall sense of self.

Additionally, results from GSE do not either support the hypothesis suggesting that active participants tend to present higher levels GSE compared with non-active participants. ${ }^{47}$ In our study, elderly active participants from the EG presented lower mean score values for GSE than those reported by their non-active partners from the CG. Similar finding were previously reported in the literature ${ }^{48}$ with active and non-active individuals with physical impairment, suggesting that non-active participants tend to inflate their GSE based on what some authors ${ }^{47,49,50}$ call "the big fish little pound effect". In our case, nonactive elderly participants may have increased their level of GSE as soon as they realized they were selected among other non-active individuals to participate in a specific research project. Meanwhile, active participants form the EG may have decreased their GSE as they compared themselves with other active individuals with higher GSE, producing a more critical opinion about themselves. Similar results have been described by Marsh $^{49}$ when assessing physical ability and physical appearance self-concepts in elite Australian athletes. The differences between elite and non-elite athletes were much smaller than initially hypothesized. Elite athletes were more critical about themselves because they tend to compare themselves with other elite athletes while non-elite athletes compared themselves with other athletes with poor performances. ${ }^{51}$

\section{Conclusion}

In summary, the results from the present study should be interpreted carefully as they may not be generalized due to the small sample size. In spite of this limitation, present results clearly evidence a positive psychological effect of exercise improving individual feelings in the physical domain, nowadays very much valued as important indicator of mental health and well-being. Self-esteem is also confirmed in elderly as a more stable psychological construct, more difficult to modify in short periods of time and less sensitive to the immediate effects of exercise as it is the case of the present intervention.

\section{Acknowledgments}

None.

\section{Conflicts of interest}

The authors declare there is no conflict of interest.

\section{References}

1. Department of Health, Physical Activity Health Improvement and Prevention-DoH. At least five a week: Evidence on the impact of physical activity and its relationship to health. 2004.

2. Thoits PA. Mechanisms linking social ties and support to physical and mental health. J Health Soc Behav. 2011;52(2):145-161.

3. U.S. Department of Health and Human Services. Mental Health: Culture, Race, and Ethnicity - A Supplement to Mental Health: A Report of the Surgeon General - Executive Summary. Rockville MD: Department of Health and Human Services, Public Health Service, Office of the Surgeon General. 2001. 
4. Coopersmith S. The antecedents of self-esteem. San Francisco: WH Freeman \& Co. Pubs; 1967:283.

5. Ferreira JP. Physical self and global self-esteem in wheelchair sport participants: a mixed method approach. Coimbra: University of Coimbra; 2006.

6. Mann M, Hosman CMH, Schaalma HP, et al. Self-esteem in a broad-spectrum approach for mental health promotion. Health Educ Res. 2004;19(4):357-372.

7. Fox KR. The effects of exercise on self-perceptions and self-esteem. In: Biddle SJH, Fox KR, Boutcher SH, editors. Physical Activity and Psychological Well-Being. London: Routledge; 2000:88-117.

8. Mirabel-Sarron C, Vera L, Samuel-Lajeunesse B. Self-esteem and depression. Ann Med Psychol (Paris). 2001;159(2):144-148.

9. Silverstone PH. Low self-esteem in different psychiatric conditions. $\mathrm{Br}$ J Clin Psychol. 2011;30(2):185-188.

10. Emery EM, McDermott RJ, Holcomb DR, et al. The relationship between youth substance use and area-specific self-esteem. J Sch Health. 1993;63(5):224-228.

11. Sullivan PF, Kessler RC, Kendler KS. Latent class analysis of lifetime depressive symptoms in the national comorbidity survey. Am J Psychiatry. 1998;155(10):1398-1406.

12. Ostrowsky MK. Are violent people more likely to have low self-esteem or high self-esteem? Aggress Violent Behav. 2010;15(1):69-75.

13. Fox KR. Advances in the measurement of the physical self. In: Duda JL, editor. Advances in Sport and Exercise Psychology Measurement. Morgantown: Fitness Information Technology Inc; 1998:295-310.

14. Netz Y, Wu MJ, Becker BJ, et al. Physical activity and psychological well-being in advanced age: a meta-analysis of intervention studies. Psychol Aging. 2005;20(2):272-284.

15. Ko JE, Lee SH. A multilevel modeling of factors affecting depression among older Korean adults. Ment Heal Soc Work. 2012;40(1):322-351.

16. ten Have M, de Graaf R, Monshouwer K. Physical exercise in adults and mental health status findings from the Netherlands mental health survey and incidence study (NEMESIS). J Psychosom Res. 2011;71(5):342348 .

17. Windle G, Hughes D, Linck P, et al. Is exercise effective in promoting mental well-being in older age? A systematic review. Aging Ment Health. 2010;14(6):652-669.

18. Atlantis E, Chow CM, Kirby A, et al. An effective exercise-based intervention for improving mental health and quality of life measures: a randomized controlled trial. Prev Med (Baltim). 2004;39(2):424-434.

19. Elavsky S, McAuley E, Motl RW, et al. Physical activity enhances longterm quality of life in older adults: efficacy, esteem, and affective influences. Ann Behav Med. 2005;30(2):138-145.

20. Hu L, Mcauley E, Elavsky S. Does the Physical Self-Efficacy Scale Assess Self-Efficacy or Self-Esteem. Journal of Sport \& Exercise Psychology. 2005;27(2):152-170.

21. McAuley E, Konopack JF, Motl RW, et al. Physical activity and quality of life in older adults: influence of health status and self-efficacy. Ann Behav Med. 2006;31(1):99-103.

22. Oken BS, Zajdel D, Kishiyama S, et al. Randomized, controlled, sixmonth trial of yoga in healthy seniors: Effects on cognition and quality of life. Altern Ther Health Med. 2006;12(1):40-47.

23. Gothe NP, Mullen SP, Wójcicki TR, et al. Trajectories of change in self-esteem in older adults: exercise intervention effects. J Behav Med. 2011;34(4):298-306.
24. Opdenacker J, Delecluse C, Boen F. The longitudinal effects of a lifestyle physical activity intervention and a structured exercise intervention on physical self-perceptions and self-esteem in older adults. J Sport Exerc Psychol. 2009a;31(6):743-760.

25. Fisher KJ, Li F. A community-based walking trial to improve neighborhood quality of life in older adults: A multilevel analysis. Ann Behav Med. 2004;28(3):184-194.

26. McAuley E, Blissmer B, Marquez DX, et al. Social relations, physical activity, and well-being in older adults. Prev Med. 2000;31(5):608-617.

27. NIH-US DHHS. Exercise \& Physical Activity: Your everyday guide. National Institute of Aging-U.S. Department of Health and Human Services. 2011.

28. Fox KR, Corbin CB. The Physical Self-Perception Profile: Development and Preliminary Validation. $J$ Sport Exerc Psychol. 1989;11(4):408-430.

29. Ferreira JP, Teixeira AM, Massart AG, et al. Assessing Self-esteem and perceived physical competence in elderly using the Physical Self- Perception Profile. Eur J Adapt Phys Act. 2013;6(2):7-18.

30. Opdenacker J, De Bourdeaudhuij I, Auweele YV, et al. Psychosocial mediators of a lifestyle physical activity intervention in women. Psychol Sport Exerc. 2009b;10(6):595-601.

31. Fox KR, Stathi A, McKenna J, et al. Physical activity and mental well-being in older people participating in the better ageing project. Eur J Appl Physiol. 2007;100(5):591-602.

32. Semerjian T, Stephens D. Comparison style, physical self-perceptions, and fitness among older women. J Aging Phys Act. 2007;15(2):219-35.

33. Sonstroem RJ, Speliotis ED, Fava, JL. Perceived physical competence in adults : an examination of the physical self-perception profile. J Sport Exerc Psychol. 1992;14:207-221.

34. Ferreira JP, Cruz MH, Salgueiro T, et al. Psychometric properties of the physical self-perception profile: a short clinical version in geriatric populations. Eur J Adapt Phys Act. 2017;10(2):3-13.

35. Chase LA. Physical Self-perceptions and activity involvement in the older population. Arizona State University. 1990.

36. Rosenberg M. Society and the adolescent self-image. Princeton, NJ: Princeton University Press; 1965.

37. Ferreira JP, Fox KR. An investigation into the structure, reliability and validity of the physical self-perception profile in non english speaking settings. Int J Appl Sport Sci. 2007;19:25-47.

38. Franklin E, Whaley BA, Howle MH. ACM's guidelines for exercise testing and prescription. 6th ed. Baltimore: Lippincott Williams \& Wilkins; 2000.

39. Batterham AM, Hopkins WG. Making meaningful inferences about magnitudes. Int J Sports Phys and Perform. 2006;1(1):50-57.

40. Hopkins WG. New View of Statistics Effect Magnitudes. 2014.

41. Martin KA, Lichtenberger CM. Fitness enhancement and changes in body image. In: Cash, TF, Prusinky T, editors. Body Image: A Handbook of Theory, Research, and Clinical Practive. New York: Guilford Press; 2002:414-421.

42. McAuley E, Blissmer B, Katula J, et al. Physical activity, self-esteem, and self-efficacy relationships in older adults: a randomized controlled trial. Ann Behav Med. 2000b;22(2):131-139.

43. Stoll O, Alfermann D. Effects of physical exercise on resources evaluation, body self-concept and well-being among older adults. Anxiety, Stress Coping. 2002;15(3):311-319. 
44. McAuley E, Marquez DX, Jerome GJ, et al. Physical activity and physique anxiety in older adults: fitness, and efficacy influences. Aging Ment Health. 2002;6(3):222-230.

45. Robins RW, Trzesniewski KH, Tracy JL, et al. Global self-esteem across the life span. Psychol Aging. 2002;17(3):423-434.

46. Spence JC, McGannon KR, Poon P. The Effect of Exercise on Global Self-Esteem. J Sport Exerc Psychol. 2005;27(3):311-334.

47. Asçi FH, Eklund RC, Whitehead JR, et al. Use of the CY-PSPP in other cultures: a preliminary investigation of its factorial validity for Turkish children and youth. Psychol Sport Exerc. 2005;6(1):33-50.

48. Ferreira JP, Fox KR. Physical self-perceptions and self-esteem in male basketball players with and without disability: A preliminary analysis using the physical self-perception profile. European Journal of Adapted Physical Activity. 2008;1(1):35-49.
49. Marsh HW. Academic self-concept: Theory measurement and research. In: Suls J, editor. Psychological perspectives on the self. Hillsdale, NJ: Erlbaum; 1993:59-98.

50. Marsh HW, Chessor D, Craven R, et al. The Effects of Gifted and Talented Programs on Academic Self-Concept: The Big Fish Strikes Again. Am Educ Res J. 1995;32(2):285-319.

51. Koyuncu M, Tok S, Canpolat AM, et al. Body image satisfaction and dissatisfaction, social physique anxiety, self-esteem, and body fat ratio in female exercisers and non-exercisers. Social Behavior and Personality: an international journal. 2010;38(4):561-570. 